\title{
$\operatorname{Div} 742$ \\ NBSIR 80-2091
}

\section{Precision Measurements on Fibrous Glass Insulation}
B. Branthover
R. Veale

Automated Production Technology Division National Bureau of Standards U.S. Department of Commerce Washington, DC 20234

\section{Siu}

Building Thermal and Service Systems Division National Bureau of Standards U.S. Department of Commerce Washington, DC 20234

November 1980

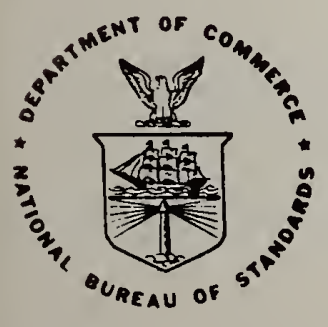

U.S. DEPARTMENT OF COMMERCE NATIONAL BUREAU OF STANDARDS 

NBSIR 80-2091

\section{PRECISION MEASUREMENTS ON FIBROUS GLASS INSULATION}

B. Branthover
R. Veale

Automated Production Technology Division

National Bureau of Standards

U.S. Department of Commerce

Washington, DC 20234

C. Siu

Building Thermal and Service Systems Division

National Bureau of Standards

U.S. Department of Commerce

Washington, DC 20234

November 1980

U.S. DEPARTMENT OF COMMERCE, Philip M. Klutznick, Secretary Jordan J. Baruch, Assistant Secretary for Productivity, Technology, and Innovation NATIONAL BUREAU OF STANDARDS, Ernest Ambler, Director 

1. Introduction

2. Material 2

2.1 Repeatability 3

2.2 Thickness Profile Procedure 3

3. Force Determination $\quad 4$

3.1 Prosedure 4

3.2 Graphs 4

3.3 Different Density Materials 5

3.4 Deformation Under Extreme Loads 5

4. Actual Thickness Profiles 6

5. Stacking $\quad 6$

6. Concluding Remarks $\quad 7$

Tables 1 and $2 \quad 8$

Table 3

Appendix - Conversion Table 11

Figure 1

Figure 2a $\quad 13$

$\begin{array}{lr}\text { Figure 2b } & 14\end{array}$

$\begin{array}{lr}\text { Figure 2c } & 15\end{array}$

$\begin{array}{lr}\text { Figure } 3 & 16\end{array}$

$\begin{array}{ll}\text { Figure } 4 \mathrm{a} & 17\end{array}$

$\begin{array}{lr}\text { Figure } 4 \mathrm{~b} & 18\end{array}$

$\begin{array}{lr}\text { Figure } 4 \mathrm{c} & 19 .\end{array}$ 
Figure 5a

Figure $5 \mathrm{~b}$

21

Figure $5 c$

22

Figure 6

23

Figure 7

24

Figure 8 25

Figure 9 26

Figure 10

27

Figure 11

28

Figure 12

Figure 13

References 


\section{PRECISION MEASUREMENTS ON FIBROUS GLASS INSULATION}

by

Brian Branthover and Ralph Veale

\section{ABSTRACT}

This paper is concerned with the technique in measuring the thickness of low density fibrous glass materials. The results will aid in the development of a Standard Reference Material for thermal resistance measurement systems.

\section{INTRODUCTION}

The recent emphasis on energy efficient homes and offices has inspired much research in the field of fibrous glass insulation. However, the persistent question still exists as to how much to use. Manufacturers want tc maximize the thermal resistance of their product and at the same time use a minimum amount of materials. Thus, a standard thickness measurement procedure must be established to insure uniformity in production. Using the thickness data, one can more precisely determine the thermal conductivity. Recently, the Building Thermal and Service Systems Division of NBS undertook the task to develop low density fibrous glass as a Standard Reference Material (SRM) for thermal resistance measurement systems. They requested the assistance of the Dimensional Metrology Group in developing a measuring technique and determining the thickness of several samples.

Proper characterization of fibrous glass material as an SRM requires information as to its thermal resistance, $R$, and factors affecting $R$. Not only are the factors in question important but also how the information for each was obtained. The thickness of a sample of fibrous glass prior to mounting in a thermal resistance system is one such important parameter in SRM characterization. The existing method for determining the thickness (ASTM C167) ${ }^{l}$ does not possess the accuracy required by NBS for SRM. Since the force had been left undefined, it became necessary to discuss an alternate technique. This report briefly describes a procedure for measuring the thickness of low density fibrous glass material. The application of this technique will aid in developing an SRM. 


\title{
2. MATERIAL
}

The low density fibrous glass material selected for development as an SRM was obtained from a domestic manufacturer* who provided the following brief description of the process of fabrication:

\begin{abstract}
"The glass melt is fed into perforated rotors. As the rotors spin at a very high velocity, the glass is extruded through the perforations into primary fibers. The fibers are further attenuated into very fine fibers by application of high temperature jets of gas in combustion. A solution of phenolic resin and water is applied to the fibers before they are collected on a moving chain conveyor. This conveyor carries the mat of glass fibers and uncured resin into a curing oven. The cured blanket is then sliced and cut into the required dimensions. The density of the final product is controlled by the speed of the conveyor and the degree of compression during the cure. To provide the most desirable characteristics, the material selected for this program was cut from the central part of the total blanket. The outer skins were discarded."
\end{abstract}

These were screened for homogeneity and five hundred (500) samples, $24^{\prime \prime} \times 24^{\prime \prime} \times 1$ 1/4", were sent to NBS. Table 1 summarizes some of the information provided by the manufacturer. Ten samples were randomly selected from the lot of 500 for characterization.

The first thing which had to be established for this type of measurement was what procedure to follow. It must be uniform and precise, and easily reconstructed in another laboratory. The process which was used throughout this project was that which made use of an LVDT (linear variable differential transformer) indicator and a height gage. However, in order to properly use the indicator a smooth hard surface must be in contact with the probe. Also, a constant force must be applied for each measurement. All measurements were made in an environmentally controlled laboratory in which the temperature was $20^{\circ} \pm .5^{\circ} \mathrm{C}$ and the relative humidity was between 30 and 40 percent.

To meet these two prerequisites (smooth hard surface, and constant force), ten aluminum discs varying in weight from $1 / 2$ to 8 ounces were made (2 each of $1 / 2,1,2,4$ and 8 ounces. Each disc was three inches in diameter and each differed in height according to its weight (see Table 2). The discs represented numerous loads which could be applied to the surface of a sample. The discs also solved the problem of a smooth surface necessary for the indicator. 'The indicator, when set to zero, exerts a force of .107 ounce; therefore, the total force is 0.1 ounce greater than the weight of the discs.

\footnotetext{
*Material by Johns-Manville Corp.**

**Certain commercial equipment, instruments, or materials are identified in this paper in order to adequately specify the experimental procedure. In no case does such identification imply recommendation or endorsement by the National Bureau of Standards, nor does it imply that the material or equipment identified is necessarily the best available for the purpose.

${ }^{\dagger}$ Conversion to SI Units are given in the Appendix.
} 
A small circle was marked on each disc. Each disc was measured at this spot for its thickness to an accuracy of \pm .0001 inch (see Table 2). The precision needed for this measurement demanded that a specific area be marked off so that readings would be taken at a constant location. This would eliminate any trouble encountered due to thickness variation of any one disc.

\subsection{Repeatability}

Before any meaningful measurements could be taken it was necessary to determine the repeatability of the measurement system. A disc was placed on a test sample so that it was not too close to the edge where it would tip or slant toward the side. The 2 ounce disc was used for a series of twenty readings at that one spot. (The 2 ounce disc was arbitrarily chosen for these measurements.) The disc was placed on the sample and then the indicator probe brought down on top of the disc. The probe was then centered inside the marked area which had been previously measured for its thickness. The meter was then zeroed. The probe was moved away to allow the disc to be raised. The disc was then placed back on the fiber glass at the same point. The probe was brought back on the mark and a reading was again taken noting any variation from zero. A total of twenty readings were taken. The standard deviation of a single reading was 0.0002 inch which indicated the system was capable of measuring the fiberglass to the desired \pm 0.001 inch accuracy.

\subsection{Thickness Profile Procedure}

In order to have an accurate picture as to the thickness of each test piece, a good profile must be made for each. To do this, enough points must be taken into consideration. It was agreed that twenty-five locations would be sufficient. Five readings were taken at each of the twenty-five spots using the method described above. During all thickness profile measurements, the height gauge and the indicator were used to produce true thickness values.

Since the test samples were nominally $24^{\prime \prime} \times 24^{\prime \prime}$, a grid system was set up as shown in figure 1 to aid in uniformity of measurements. The readings were taken at the twenty-five intersecting points and the identification number was placed at the top left above the origin as shown in figure' 1 . A co-ordinate system $(i, j)$ was formed: point A corresponds to $(1,1)$, point B to $(4,3)$, etc.

By using the two devices mentioned, the actual thickness of each piece was measured. One disc was used for preliminary profile measurements. However, through hypothesis and further data analysis, we concluded that two discs should be used for the measurement, i.e. one on top and one on the bottom. The disc on top would be directly above the one below for each reading. The reason for two discs is to cut down the error introduced by the variability of the test sample. The two discs would allow a measurement to be made between two flat and parallel three-inch contacts. This should make for a more accurate measurement since one disc does not take into account any undulations in the contour of the underside of the test piece. The lateral dilation caused by stretching the material over the bottom 3 inch disc could possibly cause measurement errors exceeding the desired 0.001 inch accuracy; therefore, to counteract the imbalance, cork board, slightly lower than the height of the disc, was inserted beneath the fiber glass 
sample. The cork board simply acted as a surface for the test piece to rest on and had no effect on the desired compression of the test piece. From that point on all thickness profile measurements were conducted with two dics.

Before further measurements were made, it was suggested that flipping the test sample might make a difference. Through several series of observations it was concluded that flipping had a very small affect on the thickness and thus it was not necessary to measure the samples both top up and bottom up.

\section{FORCE DETERMINATION}

\section{1 Procedure}

Up to this point, little has been said about what force should be used, only about different forces available. The question of force must be dealt with so that a standard testing procedure may be established.

Taking a fiber glass piece $\left(.8 \mathrm{lb} / \mathrm{ft}^{3}\right)$ with an approximate known profile, three points were selected such that none were high or low contour areas. At the first point, each of the five weights, $(.5,1,2,4$, and 8 ounces) in that order, was placed there and a thickness measurement was taken. Then at that same location, the preceding procedure was repeated, but this time the order of the weights was reversed $(8,4,2,1$, and .5 ounces). Similar data was taken at the other two points.

\subsection{Graphs}

Referring to Figures $2 a, 2 b$, and $2 c$, (one for each of the three selected points,) it is seen that the thickness dependence upon weight curves act as would be expected-greater thicknesses for lighter weights and smaller thickness for heavier weights. However, a difference between the thicknesses for increasing weights (forward direction) and that for decreasing weight (reverse direction) is evident. The average difference for the three figures was approximately .006 inch. An explanation for this might be that permanent deformation was caused by the heavier weights. This suggests that the $4 \& 8$ ounce weights might have caused the difference. The experimental verification of this hypothesis will be discussed later in this paper.

Before discussing permanent deformations under heavy loads consider the material behavior under the lighter discs. Looking at the .5 ounce disc plotted value on the curve, there seems to be a turning point where the curve starts to level off. The desire for more information at a lighter weight required a 0.25 ounce disc. The data taken from measurements using this new disc was plotted on each of the three graphs. Through examination of the data and by looking at the interface of the sample and the disc using an optical projector, we concluded that the lighter discs were resting on the peaks of surface irregularities. Figure 3 is a picture of the surface of the sample, magnified 20 times. The measurement values obtained from these weights reflected the amount of irregularities present and not the actual thickness of the test piece. From these observations the 0.25 and 0.5 ounce discs are too light for the purpose 
desired. Also, 4 ounces \& 8 ounces would be too heavy because of deformation. Therefore, the 1 or 2 ounce discs were appropriate selections for the force to be used for standard measurements. The two ounce disc was arbitrarily chosen to be the one we would use. Coupled with the probe force this made a measuring force of 2.1 ounces.

\subsection{Different Density Materials}

Force graphs were also constructed using data taken from two different nominal bulk densities $\left(1.0 \mathrm{lb} / \mathrm{ft}^{3}\right.$ and $\left.0.5 \mathrm{lb} / \mathrm{ft}^{3}\right)$. The graphs for the $1.01 \mathrm{~b} / \mathrm{ft}^{3}$ material (Figures $4 \mathrm{a}, 4 \mathrm{~b}$ and $4 \mathrm{c}$ ) were similar to the graphs for the $0.81 \mathrm{~b} / \mathrm{ft}^{3}$ except the thickness values were somewhat larger. This was probably because a more rigid material was being used. The graphs for the $0.5 \mathrm{lb} / \mathrm{ft}^{3}$ material (Figures $5 a, 5 b$ and $5 c$ ) are somewhat different from the other two graphs. Because the material was lighter, an increasing load drastically changed thickness readings, and the leveling off found on the graphs for the other two densities is not present. Therefore, it should be noted that when working with lower density materials, a lighter weight probably will be necessary to avoid possible permanent deformation.

\subsection{Deformation Under Extreme Loads}

As the load is increased, deformation is more likely to occur. Such is the case for all materials, but especially when working with such a non-rigid test material as fiber glass. It has already been shown that deformation is evident when only a four ounce weight was used. We were interested in determining the extent of the deformation at heavier loads and if the deformation was permanent. The test proceeded as follows:

1) place the 4 ounce disc at arbitrary point ( $x, y)$ and take thickness measurement.

2) place the 8 ounce disc at $(x, y)$ and take reading.

3) repeat (2).

4) repeat (1).

The series of measurements took 20 minutes. The difference between (1) \& (4) was the short-term permanent deformation caused by the heavier weight in (2) \& (3). This test kept 4 ounces as a base weight for steps (1) \& (4), but varied the heavier weight in increments of 4 ounces. Looking at the graph (see Figure 6), the points are positioned such that the force was plotted vs. the observed deformation (1)-(4). From the graph and its data table, one notes the steady Increase in deformation, also the steep rise as the force increased from 16 to 20 ounces and from 32 to 36 ounces. The value obtained for the 8 ounce force is almost exactly that obtained from the force curve of the $.8 \mathrm{lb} / \mathrm{ft}^{3}$ density when comparing the difference between cycles. Because of the short time intervals between steps (1) and (4) for each weight, a recheck of the data was done to see 
If the test piece regained any of its original thickness. After a two week period, test results on one piece showed a slight increase in thickness; however, not enough data was taken to make the measurements statistically meaningful.

\section{ACTUAL THICKNESS PROFILES}

In section 2, the thickness measurements procedure was outlined. However, it failed to specify any exact force to be used as a standard. Making use of the force data accumulated, we chose the two ounce disc as the standard (total force $=2.1$ ounces). With all preliminary tests completed, we then measured seven samples of fiber glass nominally $0.81 \mathrm{~b} / \mathrm{ft}^{3}$ (see Figures 7-13). The nonuniformity in thickness is clearly shown in these figures. Differences in thickness for a given specimen may be as large as 0.150 inch over the entire $24^{\prime \prime} \times 24^{\prime \prime}$ piece and 0.080 inch over the central 8 inch square.

\section{STACKING}

The test samples were nominally 1 1/4 inches thick. For certain thermal resistance measurements it may be necessary to use a thicker piece, or a combination of pieces. In order to meet such a demand, a stacking measurement was carried out. Various combinations of pieces allowed measurements to be made on two to seven pieces stacked on top of each other. The procedure was the same as for regular profile determination. Of the twenty-five locations only five randomly selected points were chosen for measurement. The purpose of this was to see what the relationship between the stacked value and the sum of the individual pieces. There were 4 possible outcomes:

1) The total thickness would be equal to the sum of individual thicknesses.

2) surface undulations and irregularities would cause a large positive (+) difference.

3) as more samples were stacked a larger negative (-) difference may be present because the bottom pieces were being crushed.

4) a combination of 2 and 3 would leave little difference.

It was hoped that case 1 would be the outcome, but that was not so. Noting Table 3 the difference between the stacked and the individual sums was about +0.053 inch for each interface of fiberglass-on-fiberglass; i.e., two stacked pieces gave one interface, three pieces gave two interfaces, etc. A large positive number was present and thus supported case 2 . But as more and more pieces were stacked case 3 came into play (bottom pieces crushed) since the difference per interface dips to about 0.047 inch. Thus, the results of this test dictate the need for a correction to be introduced when stacking the pieces. 


\section{CONCLUDING REMARKS}

Measurements of the thickness of low density fiber glass can be made with precision and accuracy at selected locations. For thickness measurements, applied pressures between $.009 \mathrm{lbin}^{2}$ and $.018 \mathrm{lb} / \mathrm{in}^{2}$ are considered adequate. Errors, especially with very low density material, are introduced when applied pressures are below $.009 \mathrm{lb} / \mathrm{in}^{2}$. Pressures much greater than $.018 \mathrm{lb} / \mathrm{in}^{2}$ may result in deformation of the material.

Results of measurements show a nonuniformity in thickness over a given specimen. The variation in thickness is large enough to require that measurements be made at several locations of the specimen. 
Table 1 - Summary - Manufacturer's Data on Low Density Fibrous Glass Samples Under Development as an SRM.

Density

$0.8 \pm 0.1 \mathrm{~kg} / \mathrm{m}^{3}$

Fiber Diameter

$$
\text { Micronaire } \quad 4.5 \mu \mathrm{m}(7.2 \%) * 4.1 \mu \mathrm{m}(5.0 \%)
$$

Optical Count

$\begin{array}{lll}\text { Average } & 5.7 \mu \mathrm{m} & 5.0 \mu \mathrm{m} \\ \text { Range } & 1.6-12.4 \mu \mathrm{m} & 1.5-11.7 \mu \mathrm{m} \\ \begin{array}{l}\text { Standard } \\ \text { Deviation }\end{array} & 2.4 & 2.4\end{array}$

*Figure in parenthesis is percentage phenolic resin binder material.

Table 2 - Thickness and Weight of Aluminum Discs

$\begin{array}{lc}\frac{\text { Weight }}{\text { (ounces) }} & \frac{\text { Thickness }}{\text { (inches) }} \\ 0.25 & 0.0202 \\ 0.50 & 0.0420 \\ 1.00 & 0.0880 \\ 2.00(\text { a) } & 0.1763 \\ 2.00(\mathrm{~b}) & 0.1759 \\ 4.00 & 0.3540 \\ 8.00 & 0.7060\end{array}$


Table 3 - Thickness Values of Stacked Samples

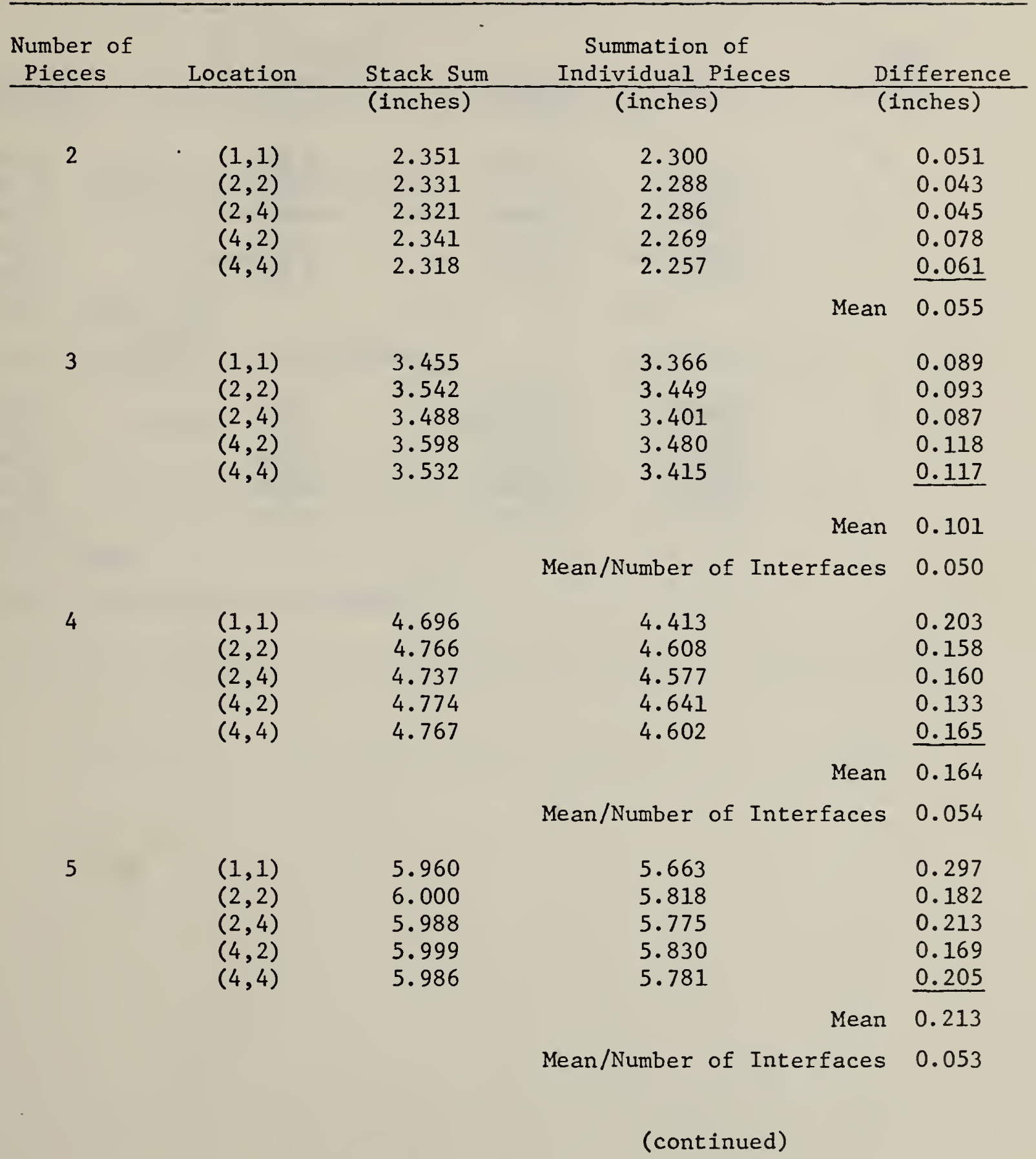


Table 3 - (Continued)

page 2

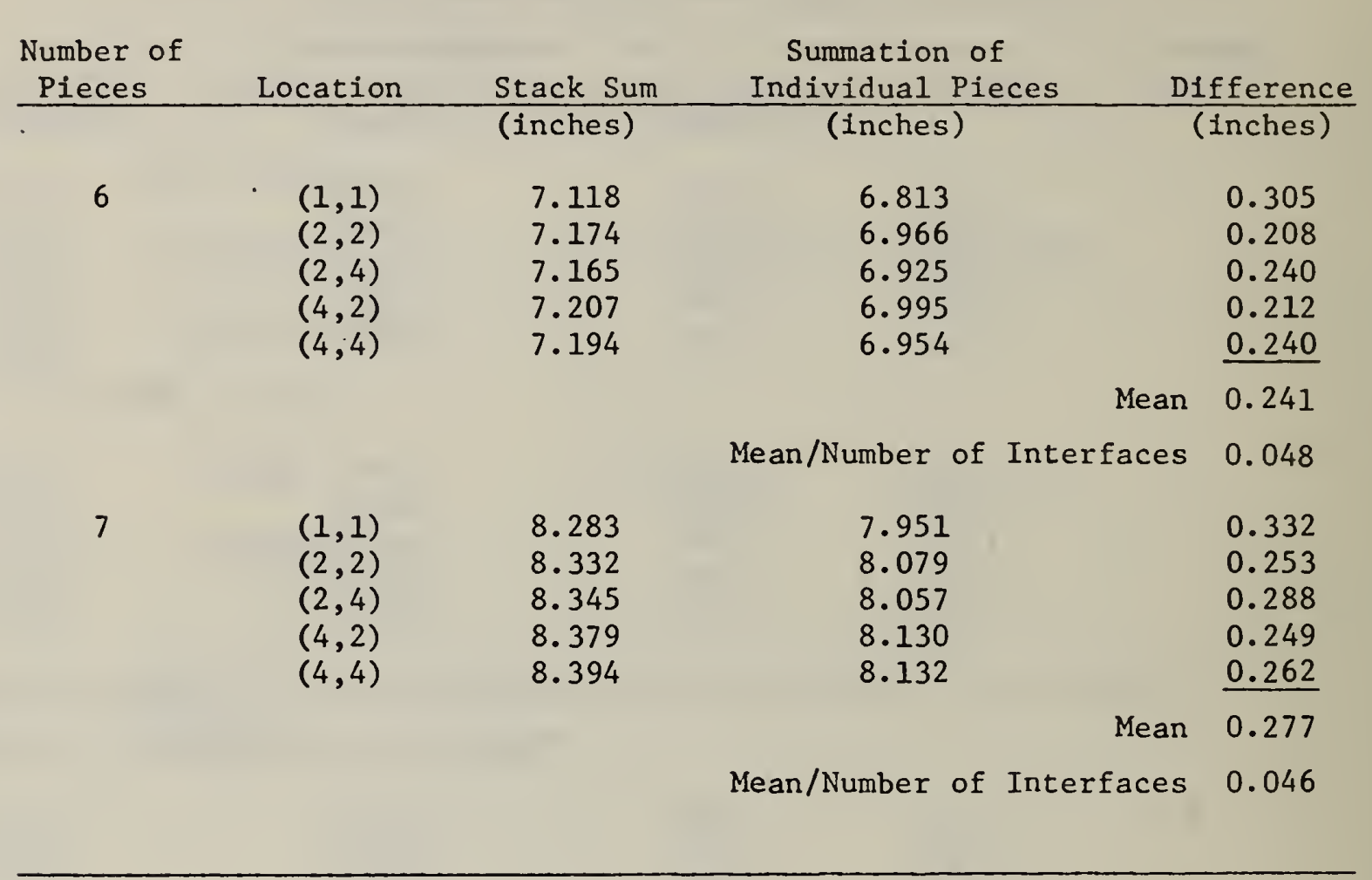




$$
\text { Appendix - Conversion Table }
$$

\begin{tabular}{lll} 
To convert & to & multiply by \\
inch & $\mathrm{cm}$ & 2.54 \\
$\mathrm{oz}$ & $\mathrm{kg}$ & $2.834952 \times 10^{-2}$ \\
$\mathrm{Ib} / \mathrm{ft}^{3}$ & $\mathrm{~kg} / \mathrm{m}^{3}$ & $1.601846 \times 10$ \\
\hline
\end{tabular}




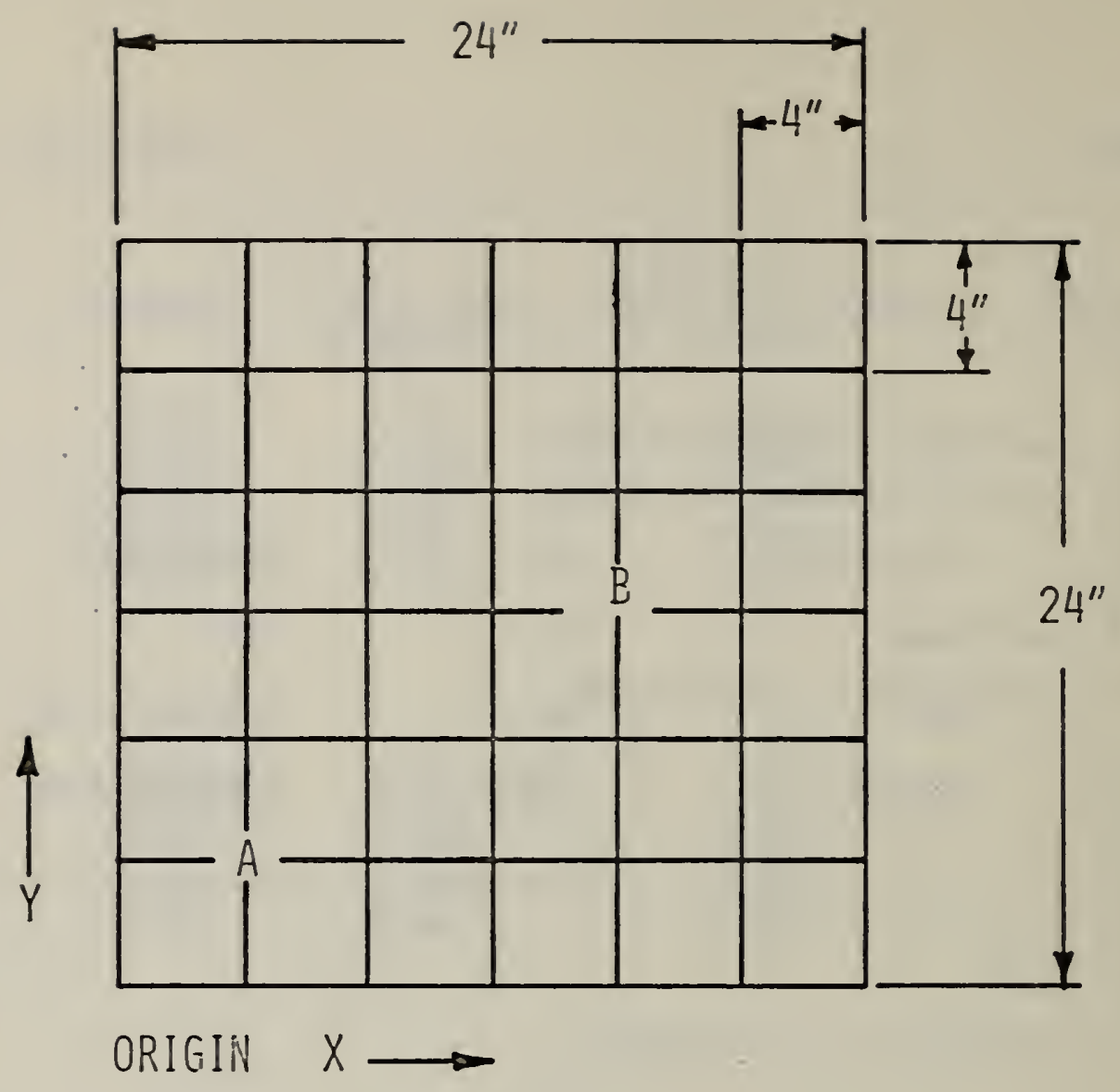

FIEURE 1 - GRID SYSTEM SHOWING MEASUREMENT POSITIONS 


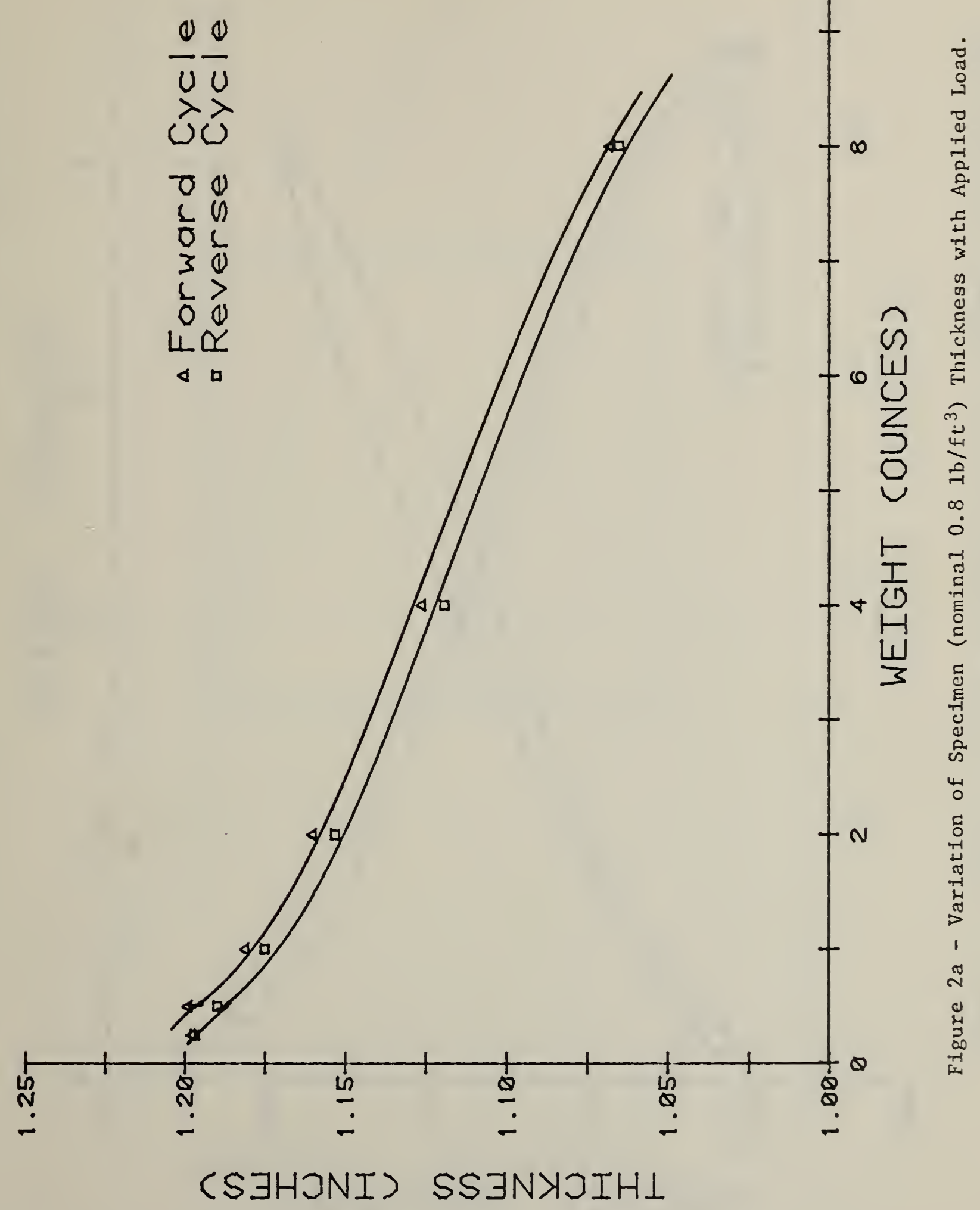




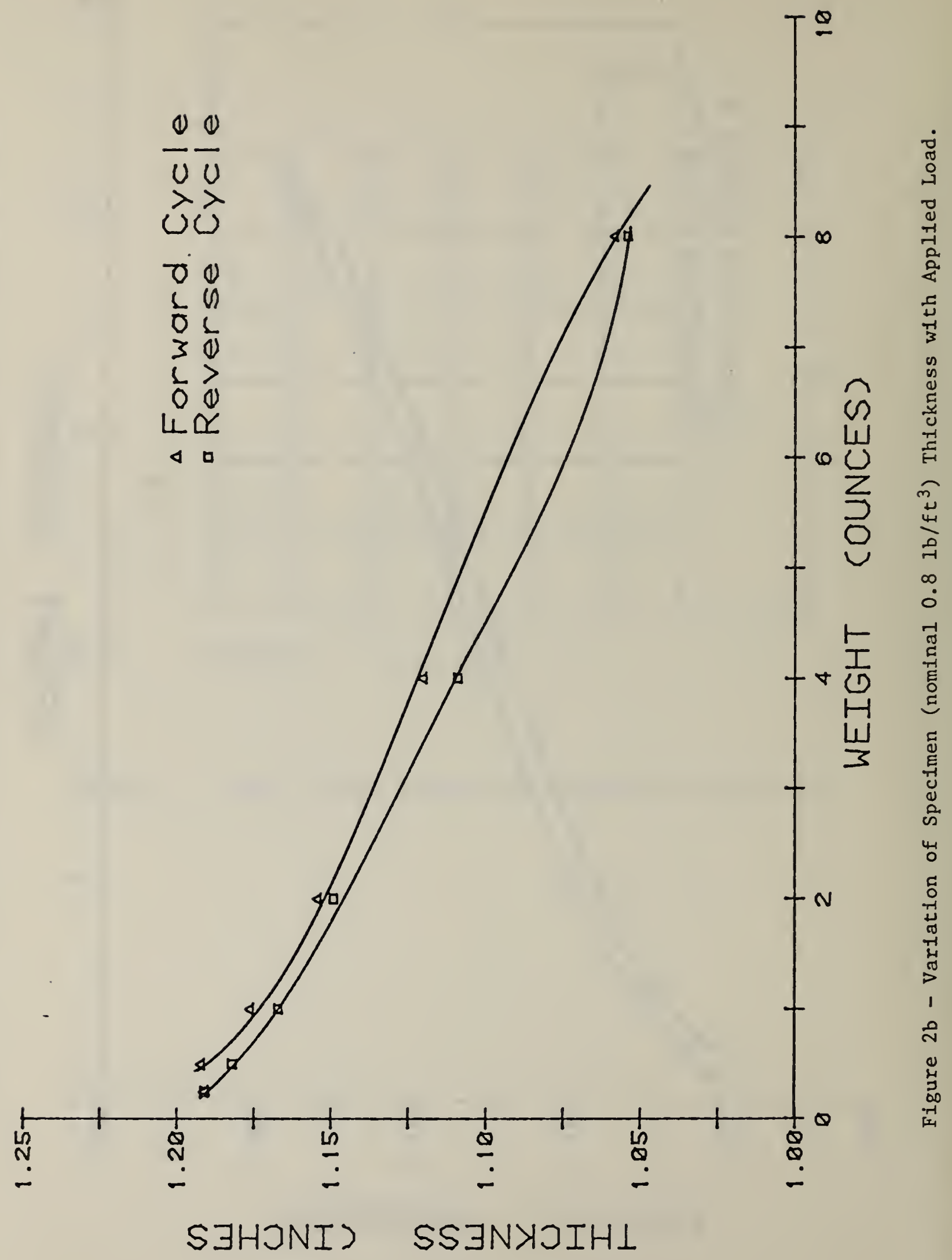




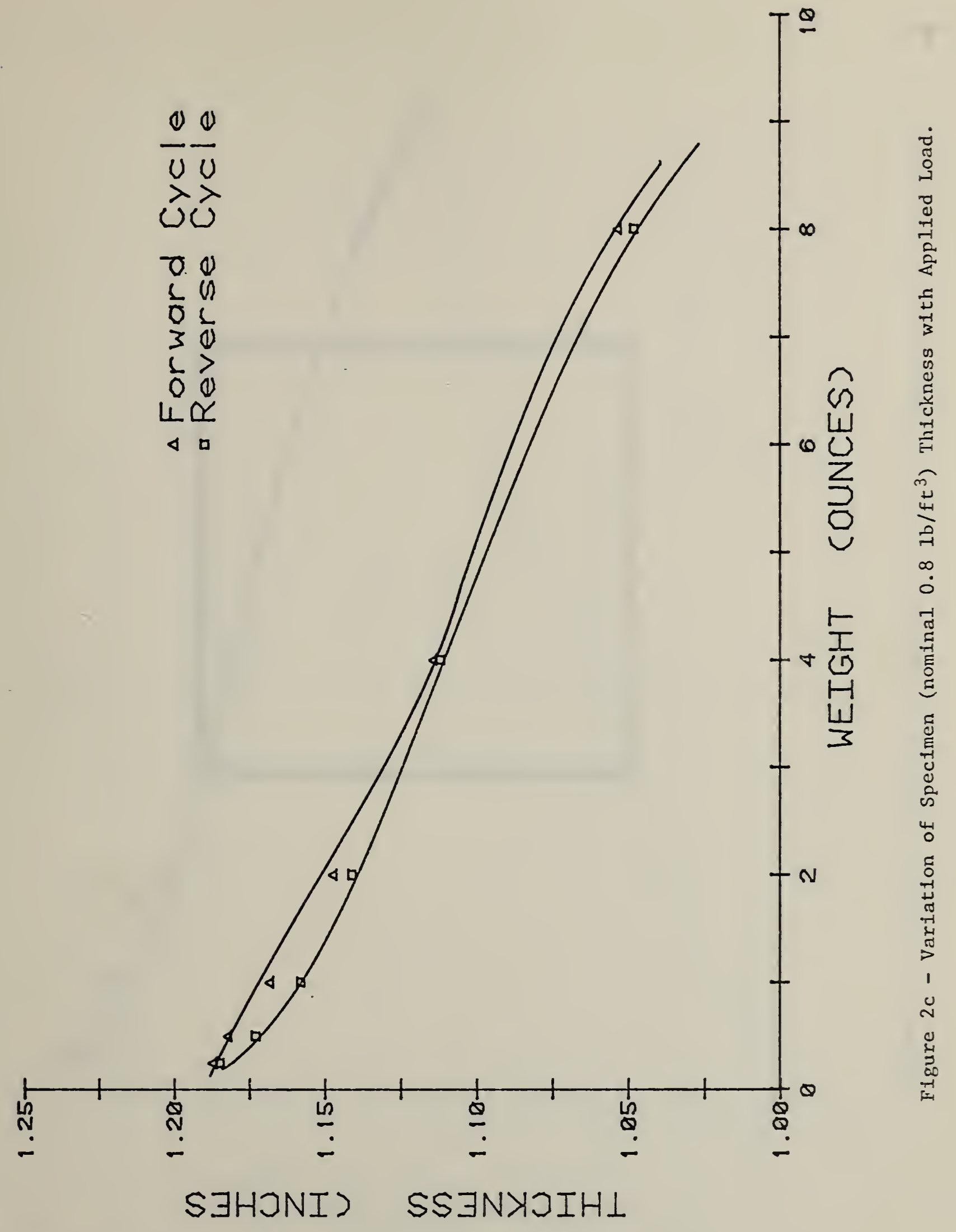




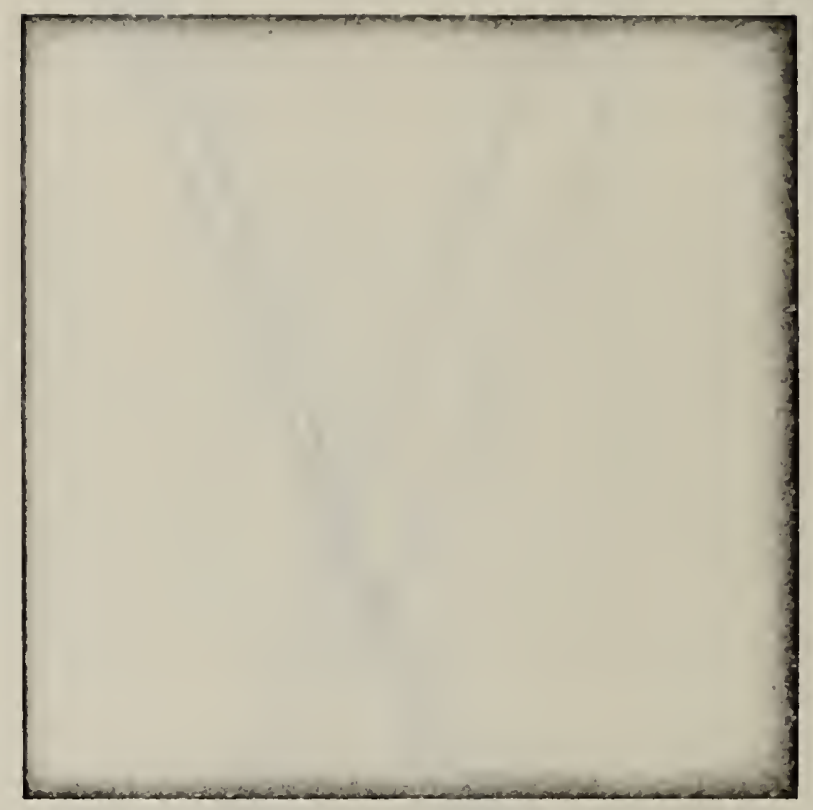

Figure 3 - Picture illustrating the surface irregularities present on each fiber glass test sample. (20X magnification). 


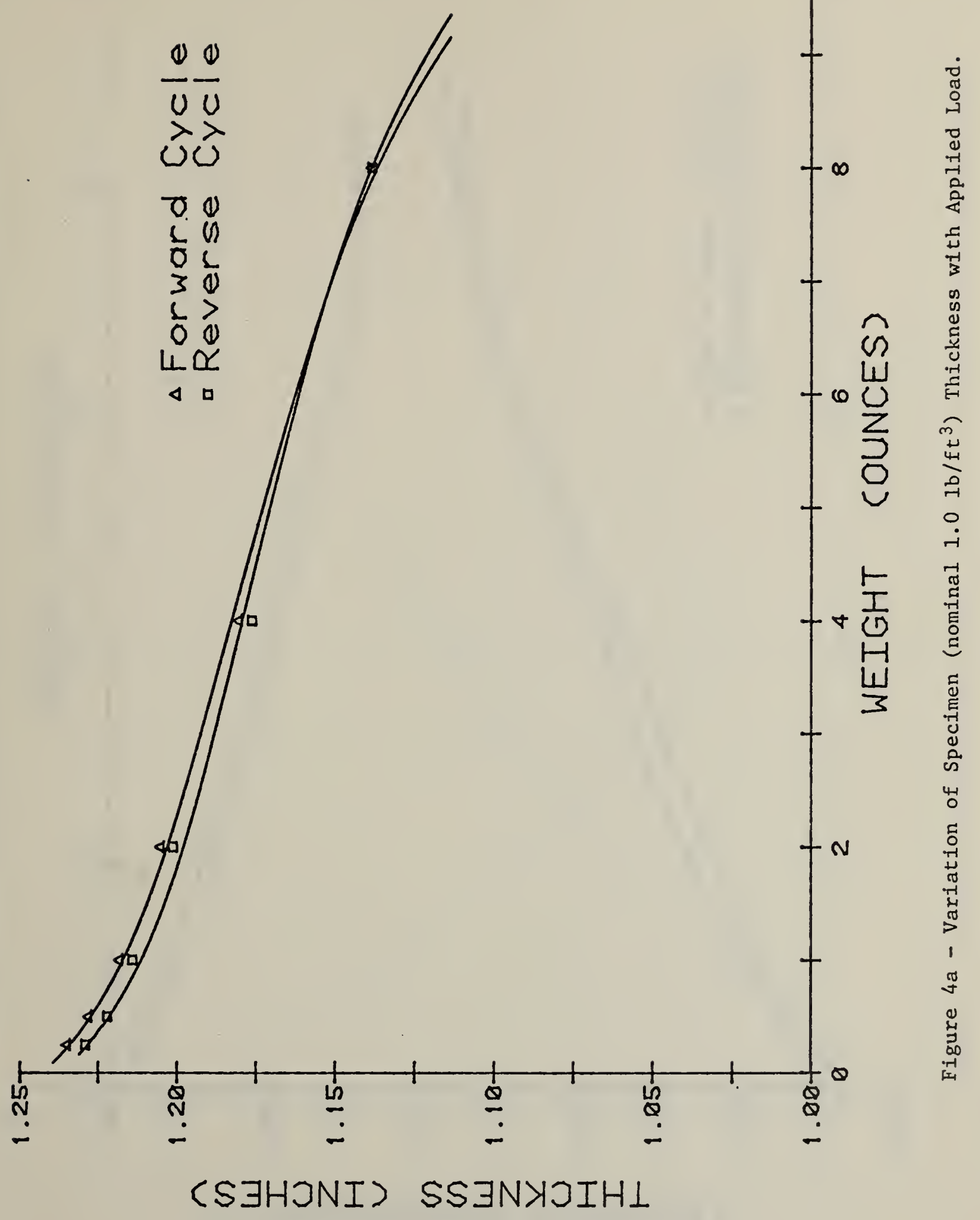




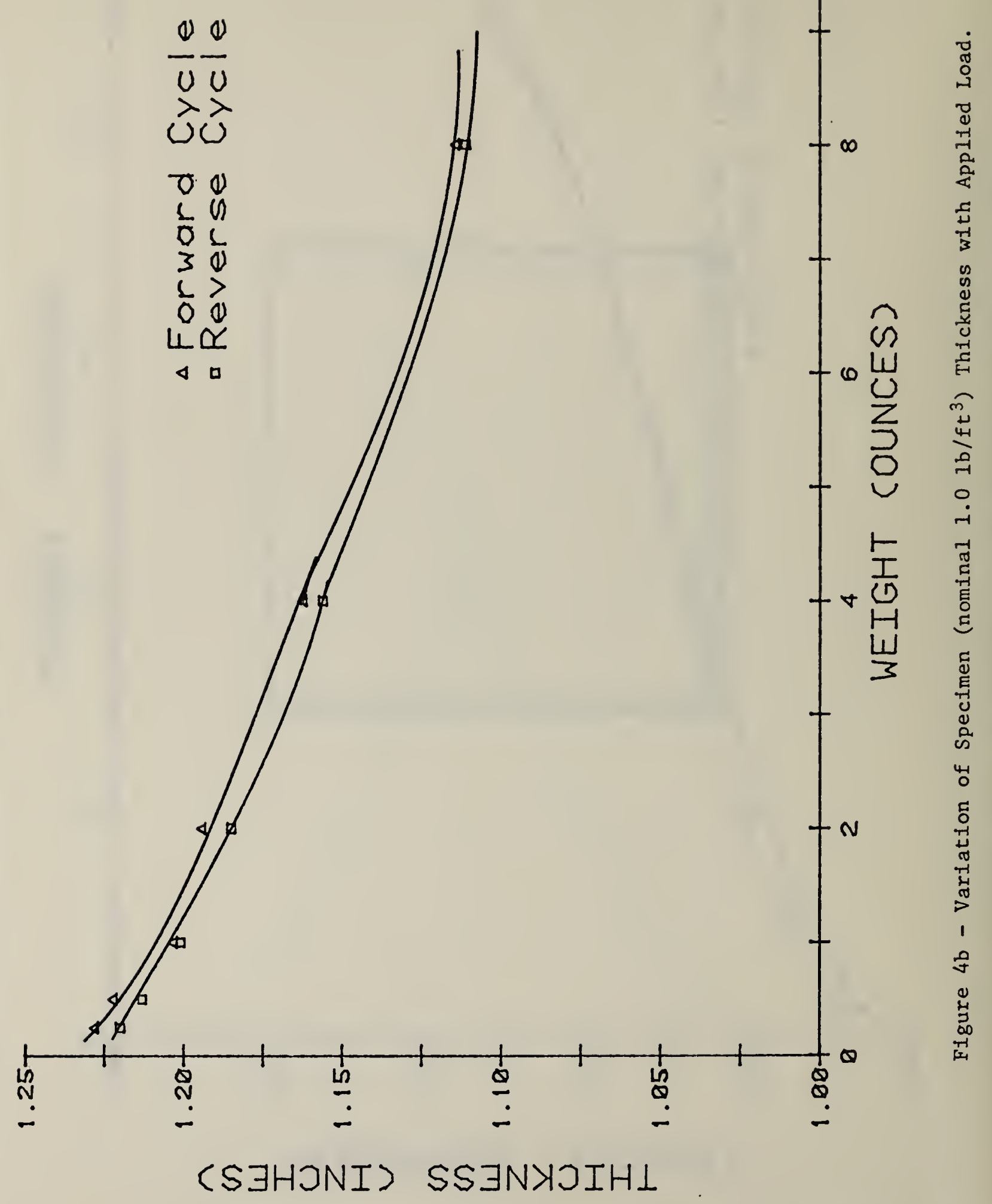




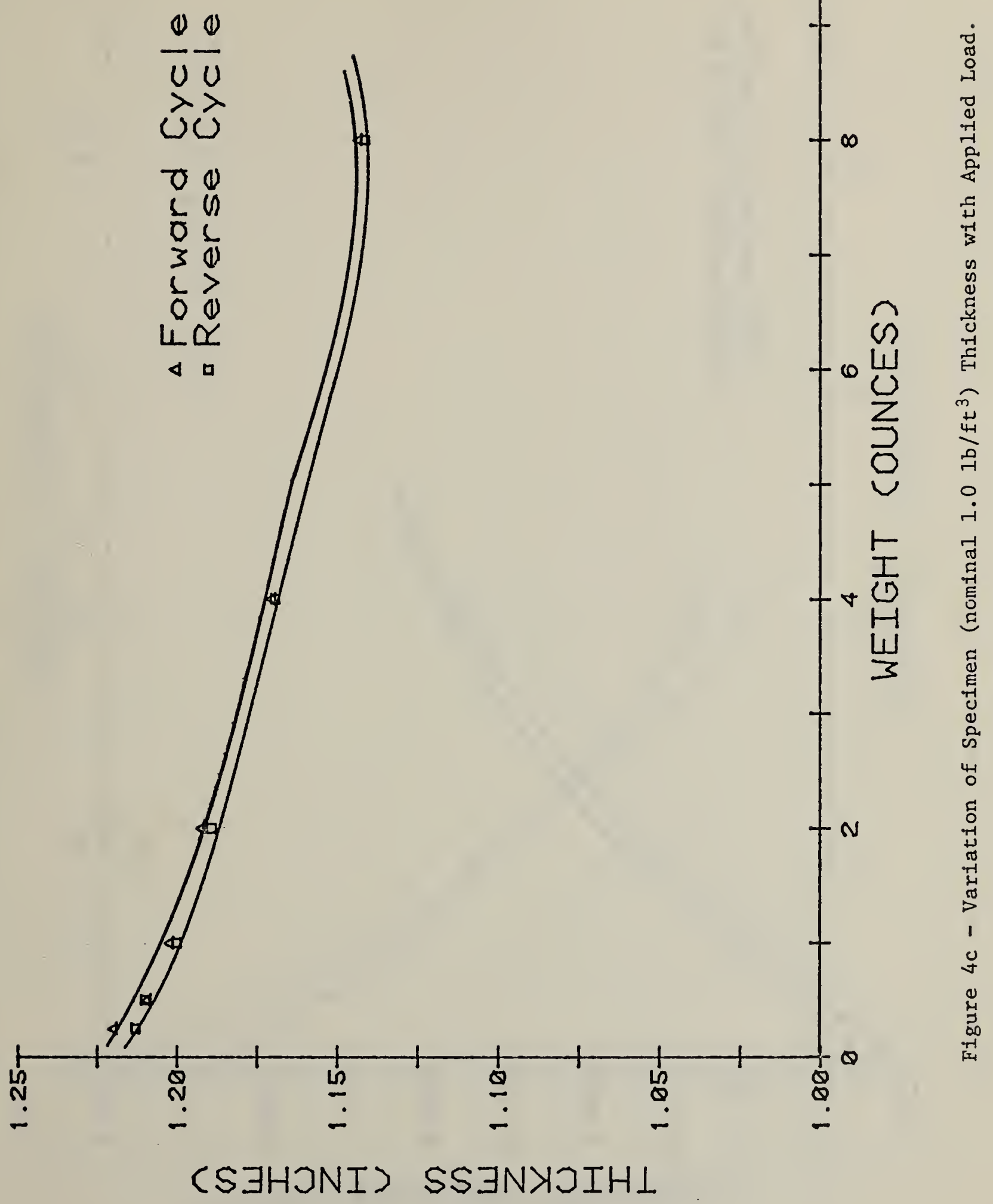



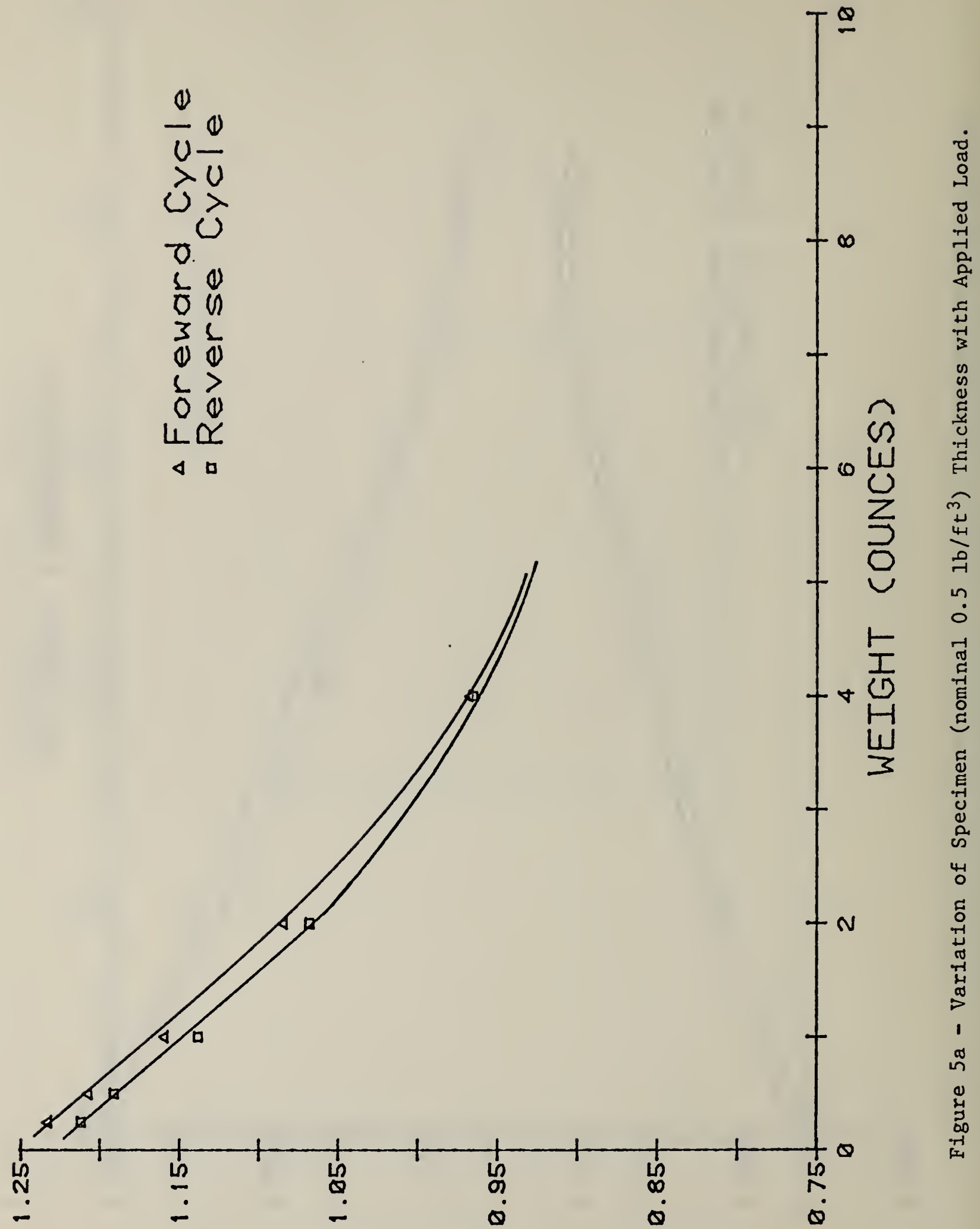

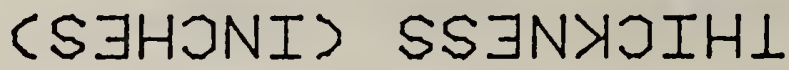



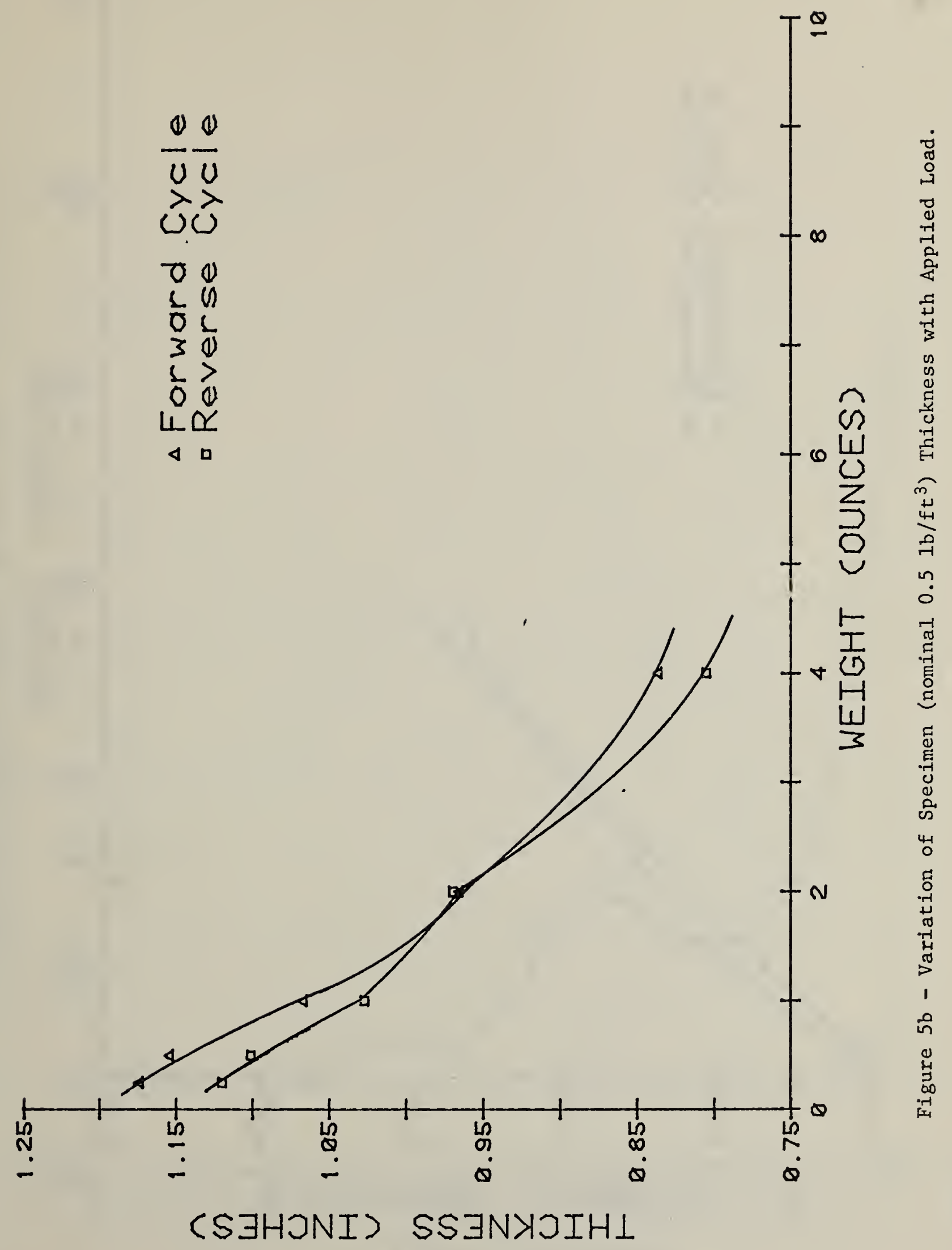

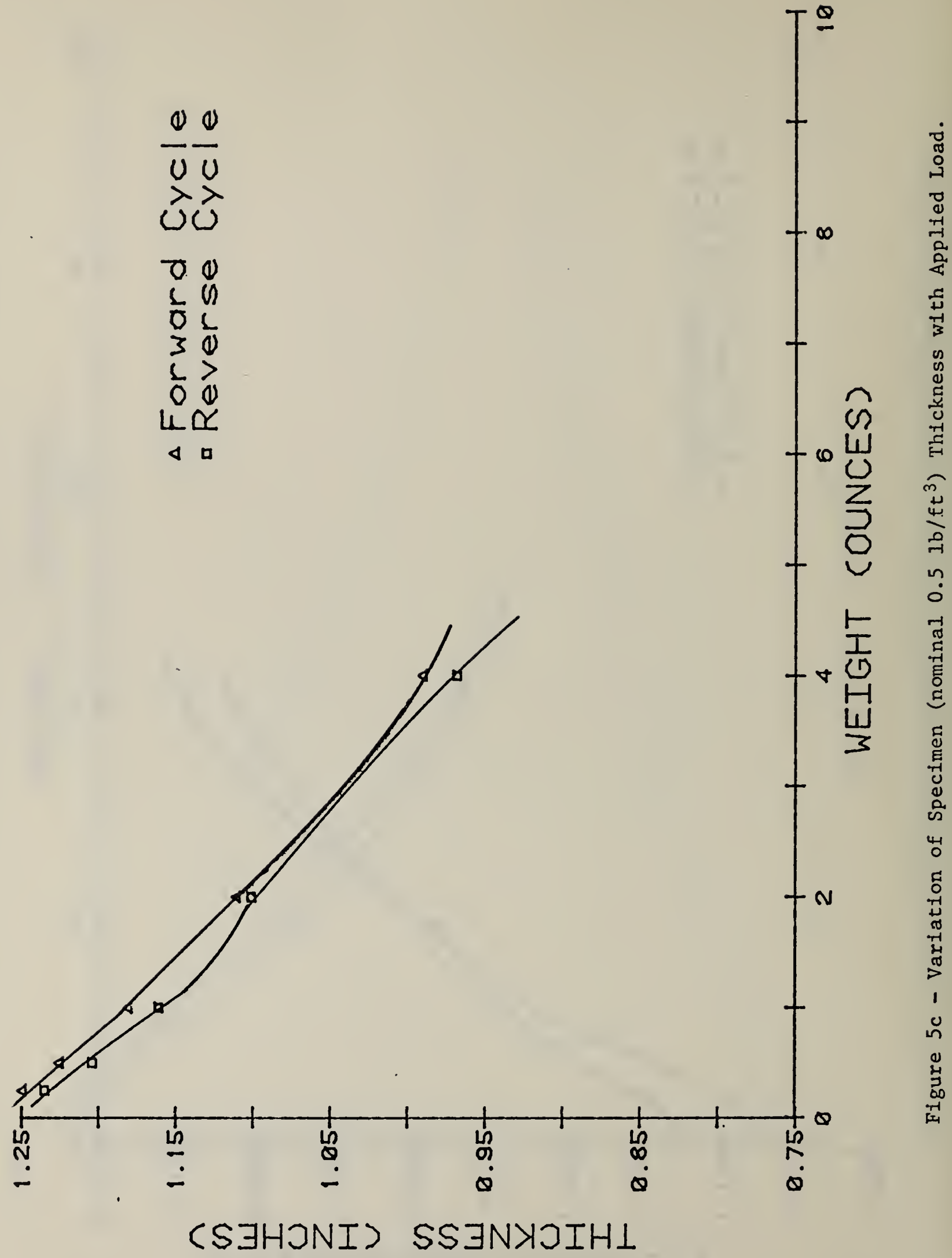


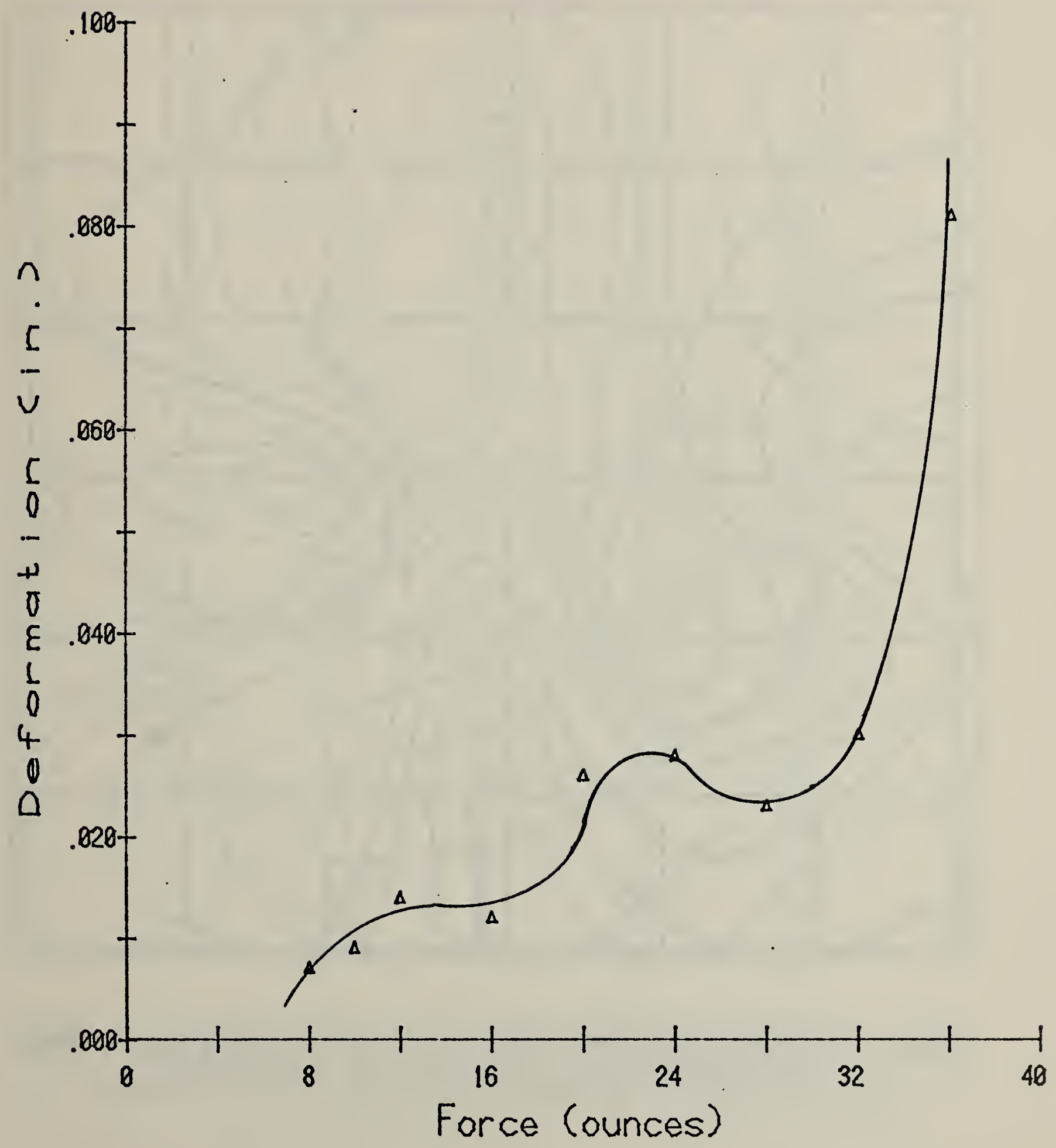

Figure 6 - Change in fiber glass thickness after application of a large load. Measurement using a four ounce force was used as reference. (0.8 $\mathrm{lb} / \mathrm{ft}^{3}$ sample) 


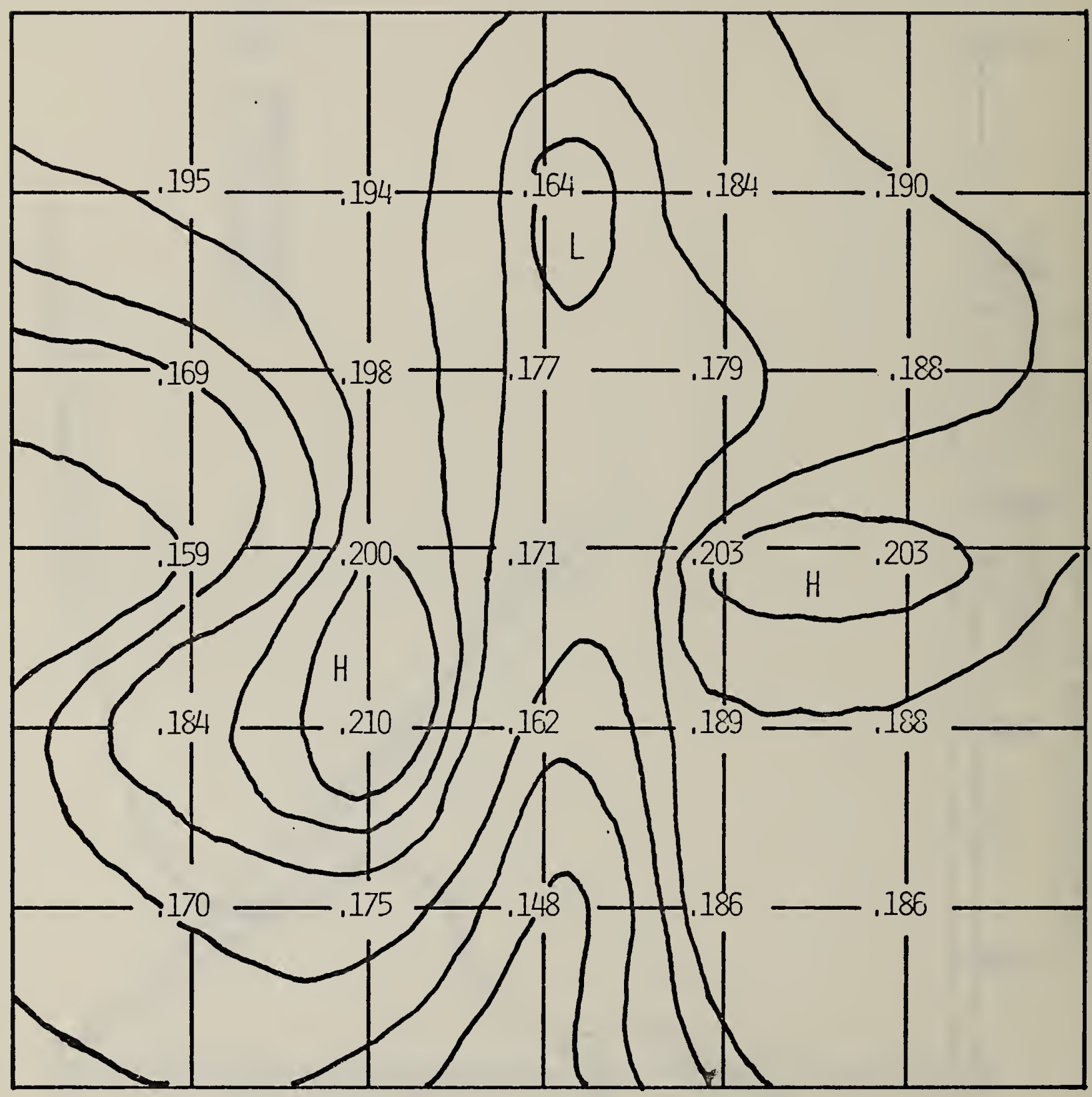

FIGURE 7 - THICKNESS PROFILE OF FIBER GLASS SPECIMEN NUUMBER 81341 (FOR ACTUAL THICKNESS ADD 1 INCH TO EACH NUMBER) 


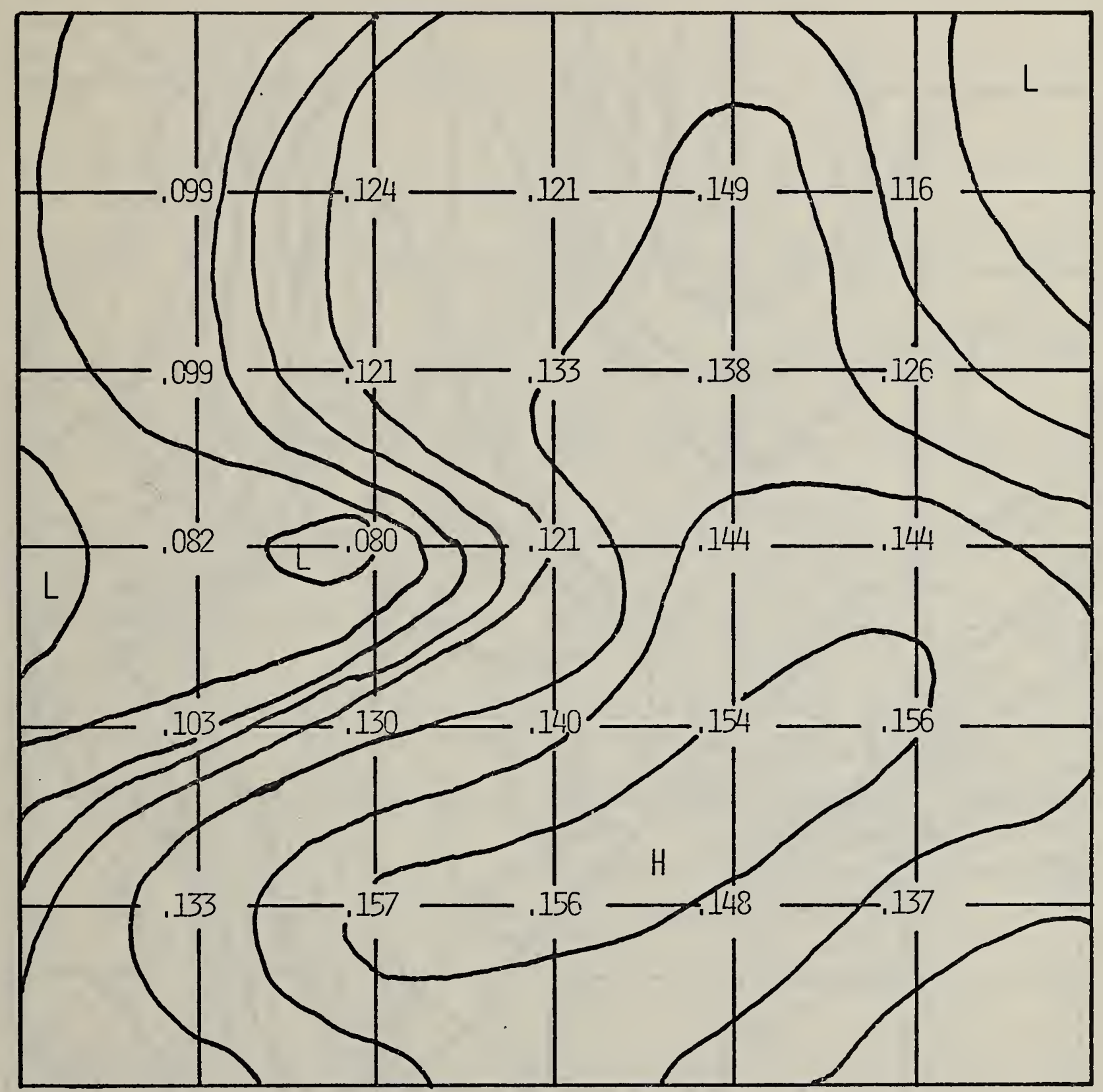

FIGURE 8 - THICKNESS PROFILE OF FIBER GLASS SPECIMEN NUMBER 81843 (FOR ACTUAL THICKNESS ADD 1 INCH TO EACH NUMBER) 


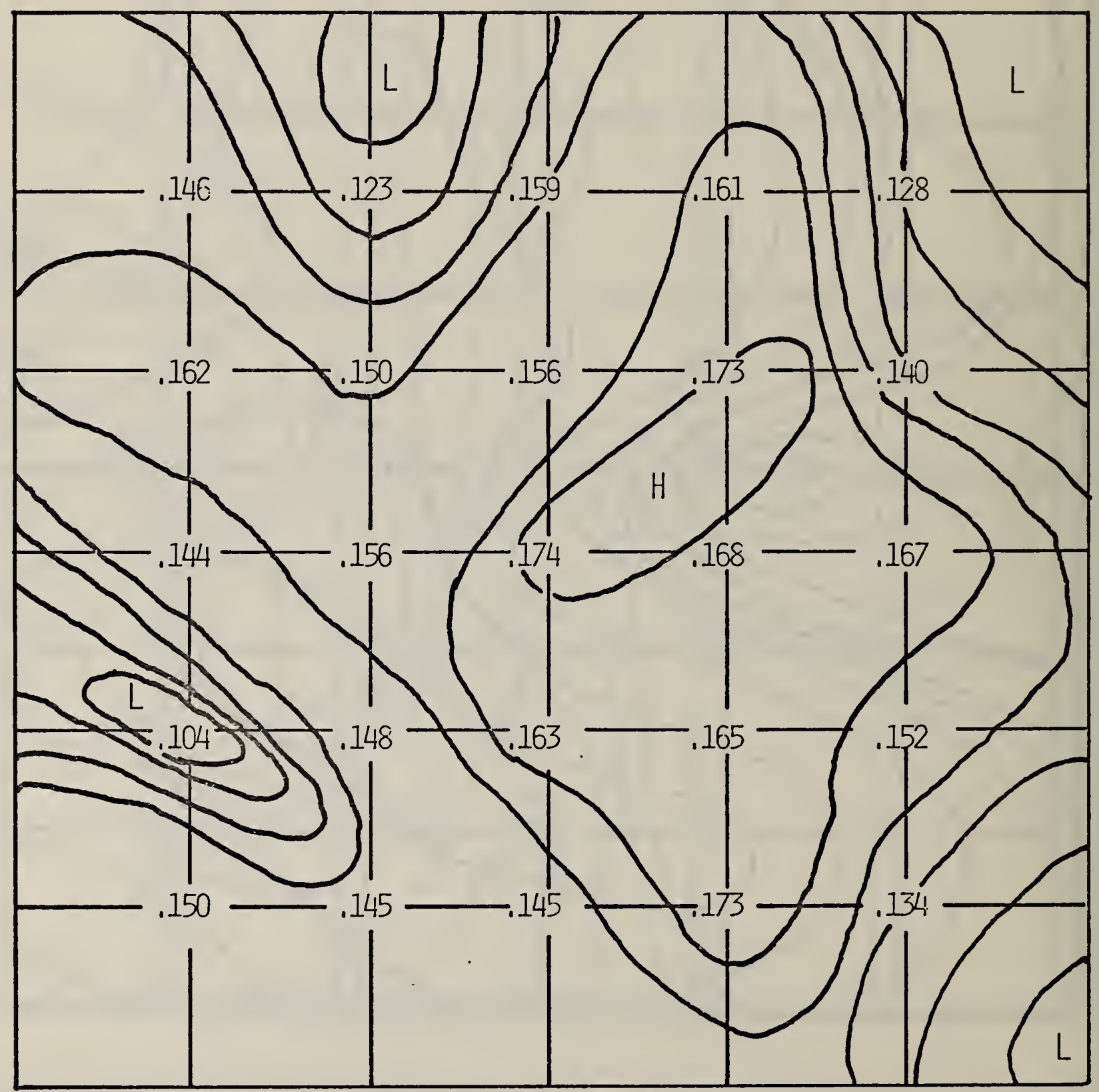

FIGURE 9 - THICKNESS PROFILE OF FIBER GLASS SPECIMEN NUMBER 82251 (FOR ACTUAL THICKNESS ADD 1 INCH TO EACH NUMBER) 


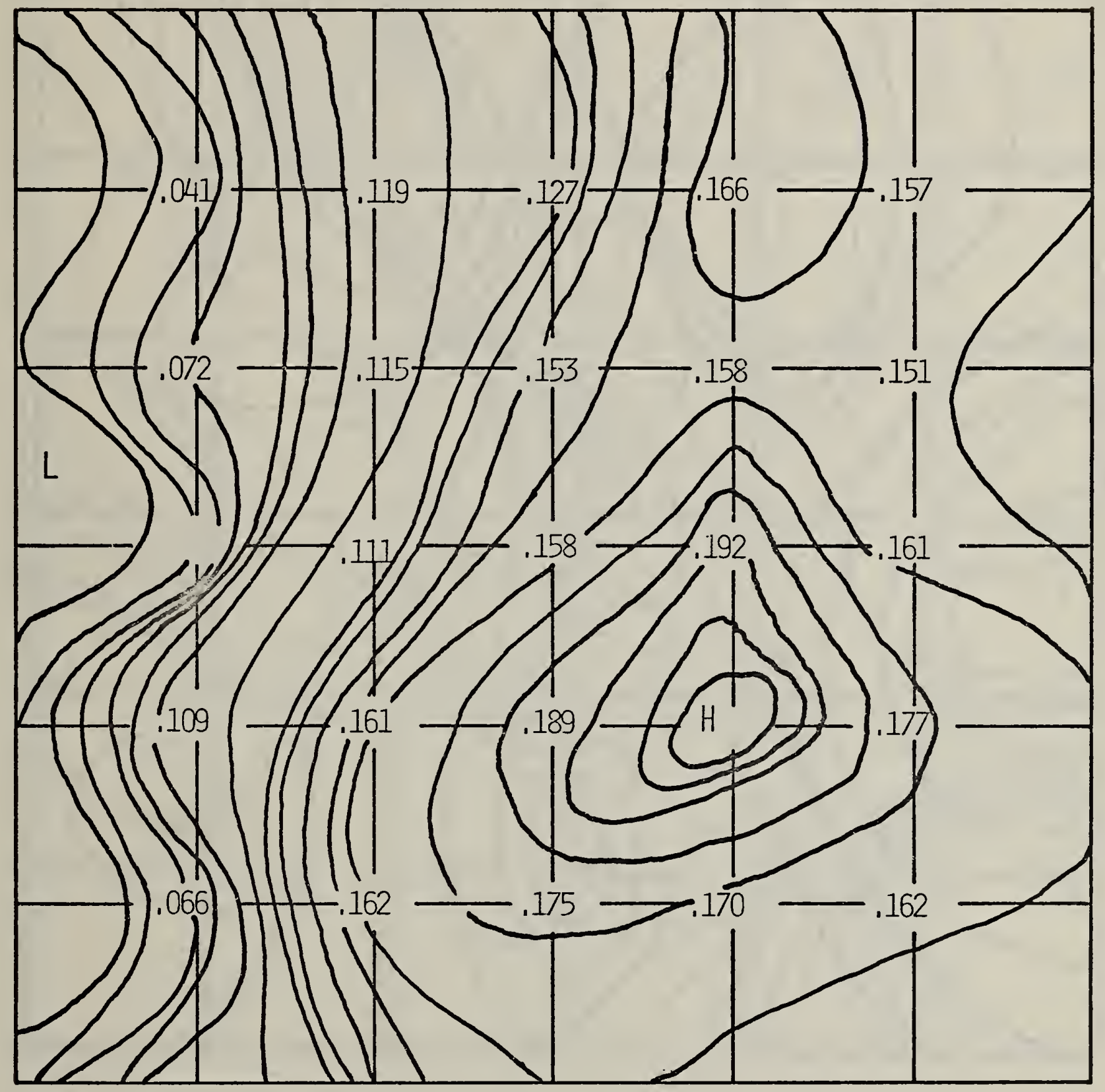

FIGURE 10 - THICKNESS PROFILE OF FIBER GLASS SPECIMEN NLMBER 84018 (FOR ACTUAL THICKNESS ADD 1 INCH TO EACH NLIMBER) 


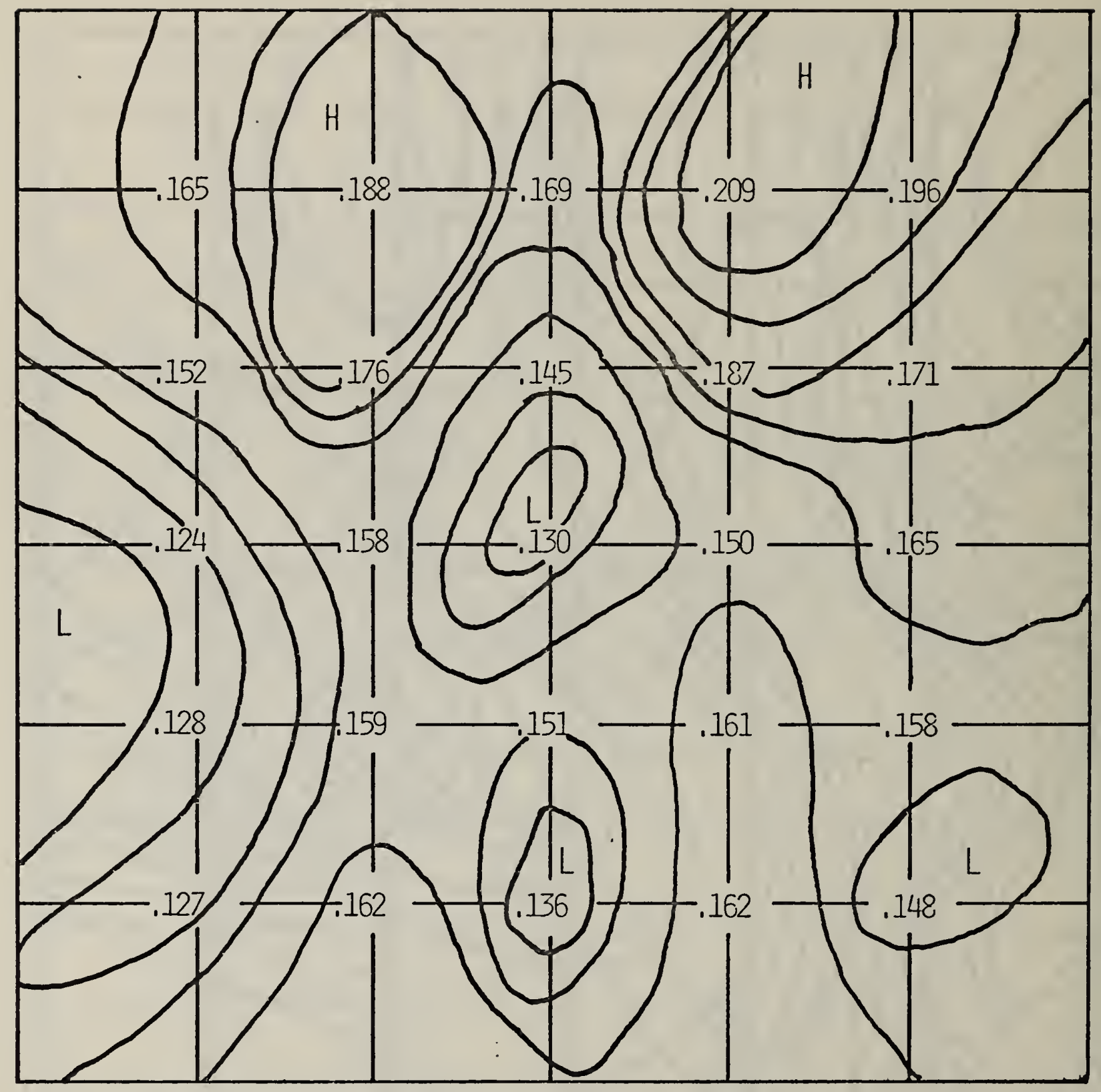

FIGURE 11 - THICKNESS PROFILE OF FIBER GLASS SPECIMEN NUMMBER 84442 (FOR ACTUAL THICKNESS ADD 1 INCH TO EACH NUMBER) 


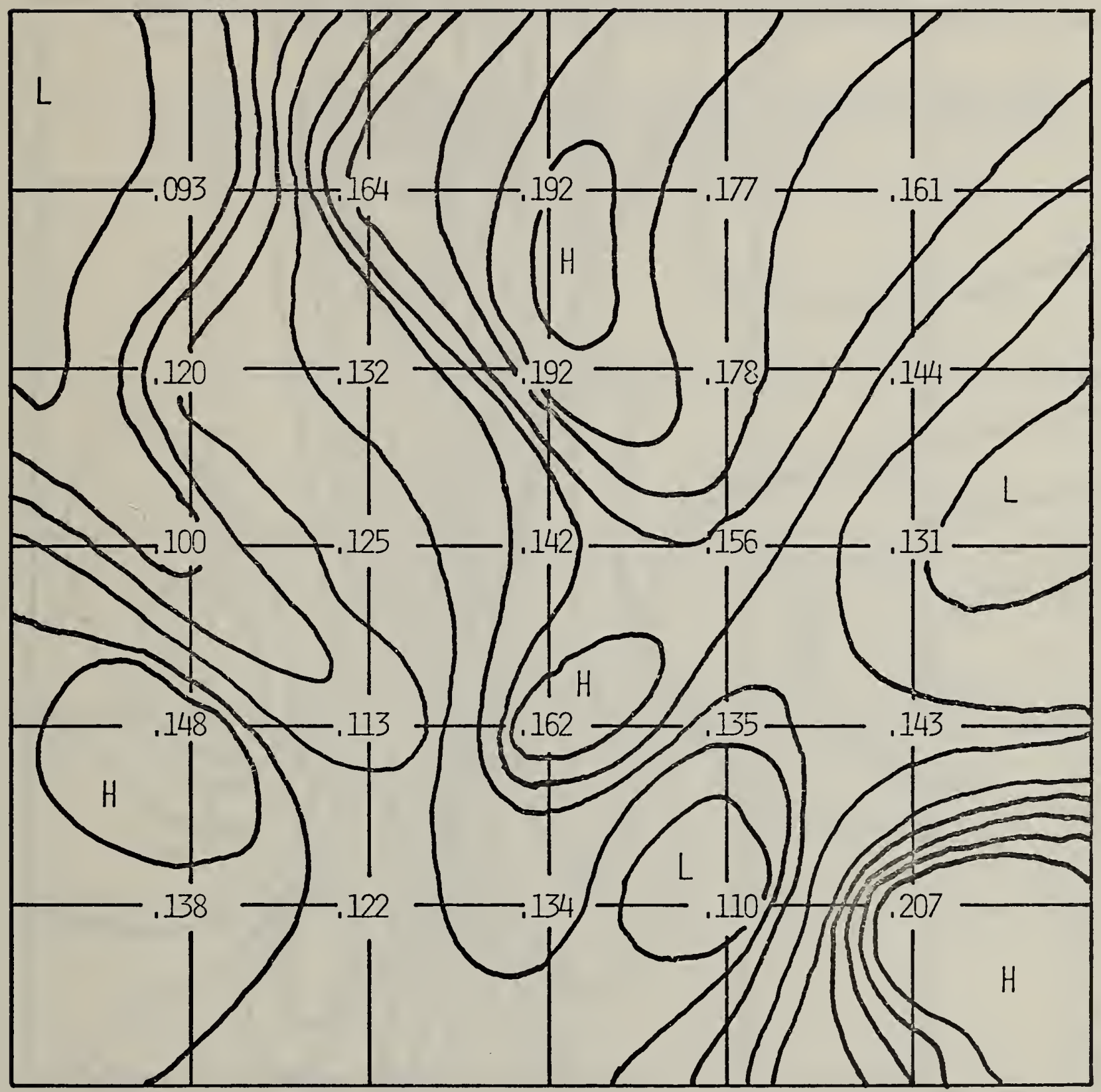

FIGURE 12 - THICKNESS PROFILE OF FIBER GLASS SPECIMEN IULMBER 84612 (FOR ACTUAL THICKNESS ADD 1 INCH TO EACH NUMBER) 


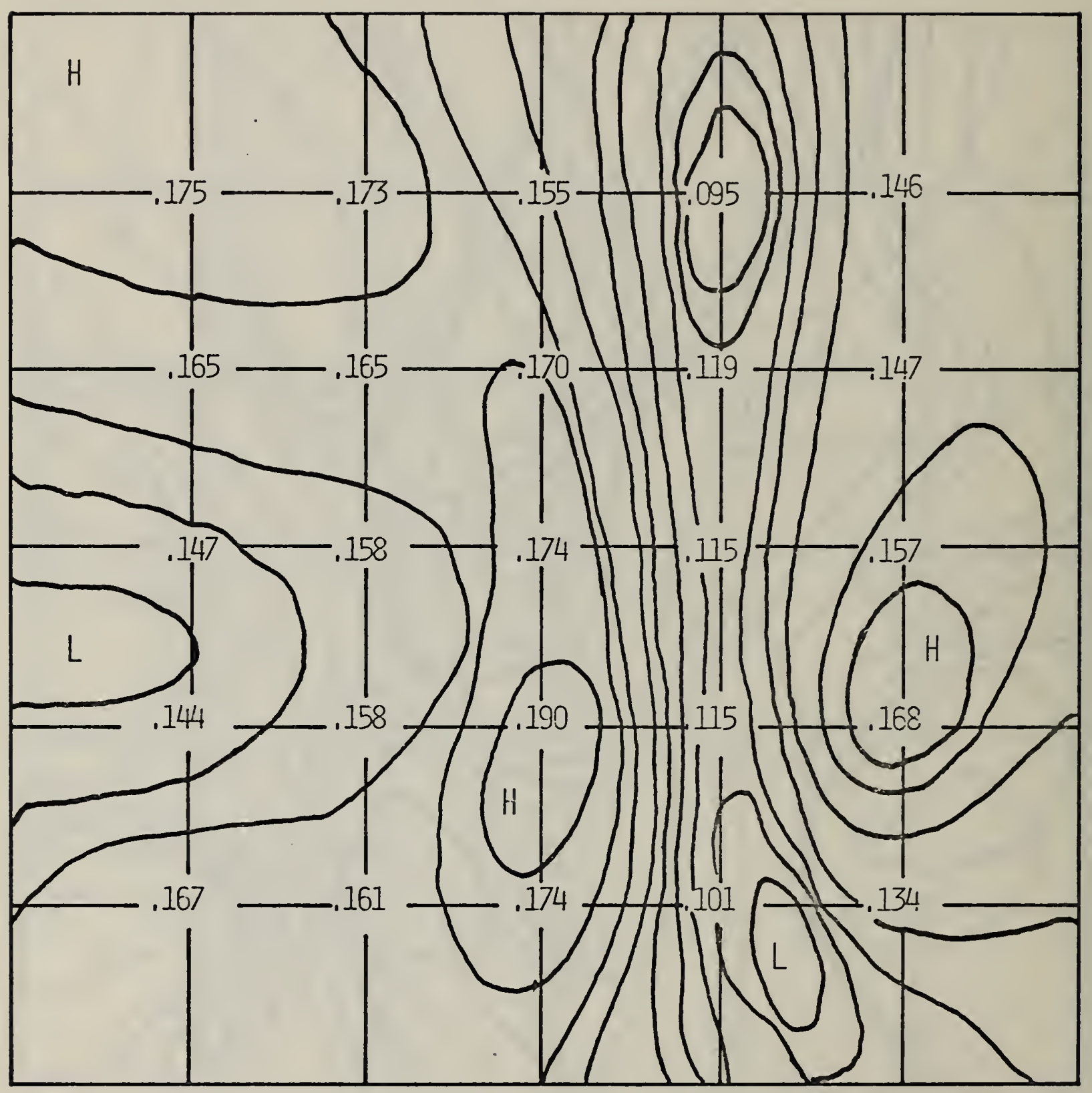

FIGURE 13 - THICKNESS PROFILE OF FIBER GLASS SPECIMEN NUI'BER 86218 (ACTUAL THICKNESS ADD 1 INCH TO EACH NUIMBER) 


\section{REFERENCES}

1) American Society for Testing and Materials, Thickness and Density of Blanket or Batt-Type Thermal Insulating Materials, ANSI/ASTM C167-64. Philadelphia: American Society for Testing and Materials, 1967.

2) American Society for Testing and Materials, Measuring Compressive Properties of Thermal Insulations, ANSI/ASTM C165-77. Philadelphia: American Society for Testing and Materials, 1977. 

NBS. II AA (REV. Q.78)

\begin{tabular}{|c|c|c|c|}
\hline $\begin{array}{l}\text { U.S. DEPT. OF COMM. } \\
\text { BIBLIOGRAPHIC DATA } \\
\text { SHEET }\end{array}$ & $\begin{array}{l}\text { 1. PUBLICATION OR REPORT NO. } \\
\text { NBSIR } 80-2091\end{array}$ & 2. Gov'r. Accession No. & 3. Recipictt's Acression Plo. \\
\hline \multicolumn{3}{|c|}{ PRECISION MEASUREMENTS CN FIBROUS GLASS INSULATICN } & $\begin{array}{l}\text { 5. Publication Date } \\
\text { November } 1980 \\
\text { 6. Performing Organization Code }\end{array}$ \\
\hline \multicolumn{3}{|c|}{$\begin{array}{l}\text { 7. AUTHOR(S) } \\
\text { B. Branthover, R. Veale, and C. Siu }\end{array}$} & 8. Performing Organ. Report No. \\
\hline \multicolumn{3}{|c|}{$\begin{array}{l}\text { NATIONAL BUREAU OF STANDARDS } \\
\text { DEPARTMENT OF COMMERCE } \\
\text { WASHINGTON, DC } 20234\end{array}$} & \begin{tabular}{|l} 
10. Project/Tasis/Nork Unit Wo. \\
11. Contract/Grant No.
\end{tabular} \\
\hline \multicolumn{3}{|c|}{ 12. SPONSORING URGANIZATION NAME ANO COMPLETE ADDRESS (Strcet, city, state, ZN") } & 14. Sponsoring Agency Code \\
\hline
\end{tabular}

\section{SUPPLEMENTARY NOTES}

Document describes a computer program; SF-185, FIPS Software Summary, is attached.

16. ABSTRACT (A 200-word or less factual summary of most significant information. If document includes a significant bibliography or literature survey, mention it here.)

This paper is concerned with the technique in measuring the thickness of low density fibrous glass materials. The new method of measurement described provides a higher degree of accuracy than previously accomplished. The new procedure determined a specific force to be used for measuring. Also, a stacking technique was carried out to see what effect placing a number of test samples on top of each other would be. The results of the entire testing will aid in the development of a standard reference material to be used for thermal resistance measurement systems.

17. KEY WORDS (six to twelve entries; alphabotical order; capitalize only the first letter of the first key word unless a proper name; soparated by semicolons)

Fiber-glass; fibrous glass; insulation; measurement; $\mathrm{R}$ value; standard reference material; thermal resistance

\begin{tabular}{|c|c|c|}
\hline $\begin{array}{l}\text { 18. AVAILABILITY } \\
\square \text { For Official Distribution. Do INot Release to NTIS }\end{array}$ & $\begin{array}{l}\text { 19. SECURITY CLASS } \\
\text { (THIS REPORT) } \\
\text { UNCLASSIFIED }\end{array}$ & $\begin{array}{l}\text { 21. NO. OF } \\
\text { PRINTED PAGES } \\
34\end{array}$ \\
\hline $\begin{array}{l}\square \text { Order From Sup. of Doc., U.S. Government Printing Office, Washington, DC } \\
20402 \text {, SD Stock No. SNO03-003- }\end{array}$ & $\begin{array}{l}\text { 20. SECURITY CLASS } \\
\text { (THIS PAGE) }\end{array}$ & 22. Price \\
\hline $\begin{array}{l}\text { X] Order From National Technical Information Service (NTIS), Springfıeld, } \\
\text { VA. } 22161\end{array}$ & UNCLASSIFIED & $\$ 6.00$ \\
\hline
\end{tabular}


